\title{
'Was it worth it?' Intrathecal analgesia for cancer pain: A qualitative study exploring the views of family carers
}

Nishi Patel, Department of Chronic Pain, Cheltenham Hospital, UK

Helen Makins, Department of Chronic Pain, Cheltenham Hospital, UK

Theresa Mitchel, Department of Health and Society, University of Worcester, UK

Jane L. Gibbins, St Julia's \& Mount Edgcumbe Hospices, Cornwall Hospice Care, UK

Juan Graterol, Royal Cornwall Hospitals NHS Trust, Truro, UK

Paul Perkins, Gloucestershire Hospitals NHS Foundation Trust and Sue Ryder Leckhampton Court

Hospice, Cheltenham, UK 


\section{Abstract}

\section{Background:}

Intrathecal drug delivery is known to reduce pain in patients where conventional systemic analgesia has been ineffective or intolerable. However, there is little information regarding the effects of intrathecal drug delivery on quality of life and function in those with advanced, incurable cancer.

\section{Aim:}

Retrospective exploration of the views of bereaved carers regarding the physical and psychosocial effects of external tunnelled intrathecal drug delivery in patients with advanced incurable cancer.

\section{Design:}

Thematic analysis of qualitative interviews with carers of deceased individuals who received percutaneous external tunnelled intrathecal drug delivery as part of their pain management, within two UK centres.

\section{Setting:}

A total of 11 carers were recruited from two UK Palliative Care centres. Family carers of adult patients who had received external tunnelled intrathecal drug delivery analgesia for cancer pain and had died between 6 and 48 months prior to contact were included. Carer relatives who were considered likely to be too vulnerable or who had lodged a complaint about treatment within the recruiting department or who had been treated directly by the interviewer were excluded.

\section{Results:}

In total, 11 interviews took place. The emerging themes were (1) making the decision to have the intrathecal - relatives described desperate situations with severe pain and/or sedation, meaning that the individual would try anything; (2) timing and knowing they were having the best - an increased access to pain and palliative care services, meant carers felt everything possible was being done, making the situation more bearable; (3) was it worth it? - the success of the external tunnelled intrathecal drug delivery was judged on its ability to enable the individual to be themselves through their final illness. Side effects were often considered acceptable, if the external tunnelled intrathecal drug delivery enabled improvements in quality of life.

\section{Conclusion:}


Carers perceived external tunnelled intrathecal drug delivery as most valuable when it improved quality of life towards the end of life, by reducing pain and side effects of conventional systemic analgesia to enable individuals 'to be themselves'. Under these circumstances, the carers judged significant side effects to be acceptable.

Keywords Pain, cancer, palliative care, pain management, intrathecal drug delivery, external tunnelled intrathecal drug delivery 


\section{What is already known about the topic?}

- External tunnelled intrathecal drug delivery (ETITDD) is effective in reducing pain when conventional systemic analgesia is inadequate or causes intolerable side effects. $\underline{1}, \underline{2}$

\section{What this paper adds?}

- Family carers described that ETITDD was used when their relatives were in desperate and intolerable situations.

- Carers judged that improvement in quality of life (QoL) and function outweighed inconveniences and side effects associated with ETITDD, for their relative.

- Several carers suggested earlier use of ETITDD.

\section{Implications for practice, theory or policy}

- These findings add to the limited previous research around the experience of ETITDD as part of palliative care and will help better inform healthcare professionals, patients and carers when considering analgesic options. These findings are applicable in any health systems which provide ETITDD as part of palliative care analgesia. 


\section{Introduction}

Moderate to severe pain is experienced by over $50 \%$ of cancer patients. $\frac{3}{-}$ The World Health Organization (WHO) analgesic ladder is effective for most patients, 4 but a significant minority $(5 \%-14 \%)$ have persistent pain despite this approach -6 and this may be an underestimation., ,,

The WHO suggests that interventional procedures may benefit this group of patients and the British Pain Society recommends intrathecal drug delivery (ITDD) when other options are inadequate or not tolerated. $\underline{-}$ An international, multicentre, randomised controlled trial shows ITDD to provide improved side effects, analgesia and some aspects of quality of life (QoL), compared with systemic medications. $\stackrel{1}{-}$ A qualitative study involving Canadian patients and health professionals earlier in the disease trajectory also suggests improved QoL. $\underline{9}$ However, as far as we are aware, there are no qualitative studies exploring the experiences of carers or patients with ITDD in the latter stages of the disease. Improved understanding of these perspectives may help when considering management options.

\section{Aim}

To explore the views of bereaved carers on the physical and psychosocial effects of analgesia by external tunnelled intrathecal drug delivery (ETITDD) in patients with advanced incurable cancer.

\section{Methods}

A retrospective qualitative approach to answer the primary question, 'What are bereaved carers' views of ETITDD for cancer pain?', including effects on pain, side effects, function and QoL.

Study sample

There is little evidence to guide the optimal time for interview. One paper recommends interviewing at least 6 months after bereavement. 10 We decided on a time- frame that allowed sensitivity around the death while being soon enough to the intervention not to impede recall.

Inclusion criteria

Carer of a patient who

- Was an adult receiving palliative care;

- Received ETITDD;

- Died between 6 and 48 months prior to contact.

Exclusion criteria 
- Considered to be too vulnerable or distressed by the clinician who managed the case;

- Who had lodged a complaint about treatment or care within the recruiting department;

- Of any patient who had been treated directly by the interviewer.

Deceased patients were identified from the Chronic Pain Team records by a clinician who was involved in their care at two locations with established ETITDD services (Gloucestershire Hospitals NHS Foundation Trust and Royal Cornwall Hospitals NHS Foundation Trust). Carer details were identified from the Patient Administration System. A letter was sent from the Chronic Pain or Palliative Care Consultant who had managed the case, along with a brief description of the study, a reply slip and a stamped addressed envelope to register interest. Those who responded were sent a Participation Information Sheet with further details. One week later, researchers contacted the carers by telephone to offer further information and to confirm participation. An interview was arranged at a convenient time and location for the carer.

Data collection

Interviews were conducted in various locations including carers' homes, hospice or hospital, following informed, written consent. A semi-structured format with a topic guide was used to explore carers' perceptions of their relatives' pain experience, management of pain, side effects and function before and after placement of the ETITDD system. All interviewers used the same topic guide and questions were revisited and altered to achieve adequate depth. Interviews took place between July 2014 and September 2015 and lasted between 48 and $120 \mathrm{~min}$. These were audio-recorded, anonymised and transcribed verbatim.

Data analysis

Each interviewer independently read and analysed their own transcripts. Codes were allocated and connections generated between the codes to identify categories, congruent with an Interpretive Phenomenological approach. $\frac{11}{}$ Data were read by other team members to gain familiarity and assist with category generation. Once categories had been agreed, the researchers worked extensively together to develop emerging themes and to agree on illustrative quotes. To promote trustworthiness in the analysis, the team discussed at length where categories should be housed within themes, and retitled themes to reflect the meaning of interviews.

Ethical considerations

We recognised that the interview process had the potential to distress the interviewee. Support team contact details were provided for local bereavement charities and the Hospice and the team offered to contact the carers' general practitioner. Ethical approval was agreed by Solihull West Midlands NRES Committee (REC 13/WM/0473). 


\section{Results}

A total of 17 carers were sent an invitation letter and 11 were interviewed. All carers interviewed were close family members of patients who had ETITDD for pain control in the context of advanced progressive malignancy.

\begin{tabular}{|c|c|c|c|c|c|c|c|}
\hline Gender & Age at death & Main Site of pain & $\begin{array}{l}\text { Primary cancer } \\
\text { diagnosis }\end{array}$ & $\begin{array}{l}\text { Primary place } \\
\text { of care after } \\
\text { ETITDD } \\
\text { insertion }\end{array}$ & Place of death & $\begin{array}{l}\text { Time between } \\
\text { insertion of } \\
\text { ITDD and } \\
\text { death }\end{array}$ & $\begin{array}{l}\text { Time between } \\
\text { death and } \\
\text { interview }\end{array}$ \\
\hline $\begin{array}{l}\text { Female-5 } \\
\text { Male }-6\end{array}$ & $\begin{array}{l}<50 \text { years }-1 \\
50-60 \text { years }-6 \\
>60 \text { years }-4\end{array}$ & $\begin{array}{l}\text { Lower back - } 3 \\
\text { Thoracic spine-1 } \\
\text { Pelvis - } 6 \\
\text { Hip and leg -1 }\end{array}$ & $\begin{array}{l}\text { Bowel - } 2 \\
\text { Bladder -3 } \\
\text { Breast - } 2 \\
\text { Osteosarcoma - } 1 \\
\text { Prostate - 1 } \\
\text { Lung - 1 } \\
\text { Pancreas - 1 }\end{array}$ & $\begin{array}{l}\text { Home -6 } \\
\text { Hospice- } 5\end{array}$ & $\begin{array}{l}\text { Home - } 3 \\
\text { Hospice - } 7 \\
\text { Nursing home - } 1\end{array}$ & $\begin{array}{l}<5 \text { weeks }-4 \\
5.10 \text { weeks - } 2 \\
10-20 \text { weeks }-2 \\
>20 \text { weeks - } 3\end{array}$ & $\begin{array}{l}<1 \text { year }-2 \\
1-2 \text { years }-2 \\
2-4 \text { Years }-2 \\
>4 \text { years }-5\end{array}$ \\
\hline
\end{tabular}

ITDD: intrathecal drug delivery, ETITDD: external tunnelled intrathecal drug delivery.

ITDD: intrathecal drug delivery; ETITDD: external tunnelled intrathecal drug delivery.

Three themes emerged from the data:

1. Making the decision to have the ETITDD;

2. Timing and knowing they were having 'the best';

3. Was it worth it?

Theme 1: making the decision to have the ITDD

In total, 10 of the 11 carers recalled an inability to achieve acceptable pain relief prior to the ITDD, and this was the major factor limiting many activities of daily living:

The pain got worse and worse and she was literally crawling on all fours and just trying to find a position to relieve her pain. (Participant 8)

Carers recalled significant cognitive compromise caused by systemic analgesia and related how this impacted upon the QoL of their relative in many ways, including inability to communicate lucidly with family and friends or to participate in important activities:

They knocked him out, so he's got no life, so he's there and he's not in pain but he's not with us and he didn't like that and we didn't like it. (Participant 9)

Carers described their relative experiencing progressively worsening pain, loss of function and associated distress, resulting in admission to an inpatient setting for pain management:

The pain became quite serious from summer and then towards Christmas it became quite unbearable. We went away at Christmas but she couldn't stand it so we had to come back Boxing Day and that was really the end. She couldn't cope with the pain. She had a PCA, but 
it was not strong enough to deal with the pain. They couldn't cope with her pain in hospital. (Participant 4)

Carers described the hopes held by the patient and family when the concept of ETITDD was introduced:

That is primarily what our aim was just to get the pain under control so she could come home and still be in bed at home, you are on the bed at the moment and you have got to take this risk so this is continuous and you are comfortable, you can have conversations, you can engage with the kids. (Participant 1)

Carers described discussion of ETITDD as a method of pain control and the decision-making process. Some took the opportunity immediately, while others weighed it up:

Her legs were gone before the pump operation (ITDD) so I think that's what in the end made us say yes, go for it because if there had been a chance she could walk then we probably wouldn't have gone for it but because her legs had gone by this point she said yes, would take anything to stop the pain. (Participant 3)

Carers reported various factors, specific to individual patient priorities, that contributed to the decision to have ETITDD and the common theme was the hope that ITDD would enable the patient some control over their situation.

Theme 2: timing and knowing they were having 'the best'

Some carers appreciated that physicians had 'correctly' estimated the appropriate time to insert the ETITDD avoiding loss of the ability to communicate or reduced consciousness:

I think it was perfect timing because the pain was becoming such that he was either going to have no quality of life or he was going to have some, he was still going to be conscious, he was still going to be a bit more mobile and when he was approached with it, it was the perfect time. Definitely, definitely because he was still able to say what he wanted to do. (Participant 9)

Others carers were disappointed, as they felt that the ETITDD had been inserted too late:

I really wish they had done it earlier on when he was in so much pain when they couldn't get hold of it. Instead of having 10 days I might have had a month or 6 weeks, you know with him (without pain). (Participant 11)

Family carers described the distress of watching their relative in pain and the relief and importance of knowing that he or she was receiving the best possible pain control:

We knew that he was going to die, but when and how was in the lap of the gods and needed to be managed in the best possible way. And we felt that there (in the hospice), those issues were being addressed and that's what mattered. You would be a suitable candidate to have one of these, it will address the levels of pain you are experiencing and hopefully make you feel better and have a better quality of life. (Participant 6) 
An increased level of specialist support was provided with ETITDD and carers appreciated the optimal support and care. In both geographical areas, the patients with ITDD had access to a 24/7 days a week to a specialist advice service, hospice inpatient admission and ETITDD trained staff in the community. Timely access to this support was recognised as very important, particularly when the patient was at home:

I felt supported. The hospice's support was very important, I knew I could pick the phone up at any time, day or night and speak to them and that was important. (Participant 5)

A few of the carers believed the ETITDD may have helped prolong life by the resultant reduction in systemic analgesia:

I think if he had gone down the route of not doing it, he would have died a lot sooner, completely probably a year sooner. (Participant 9)

Theme 3: was it worth it?

The perceived benefits of ETITDD were expressed by the carers through categories including 'quality of life', 'being themselves' and 'being normal' for longer. Nearly all carers reported a significant improvement in pain control once the ETITDD dose was optimally titrated and several reported significant reductions in side effect burden:

He wasn't so confused. He wasn't drugged up to the eyeballs so that you know he was getting confused and sleeping all the time he was more alert, that was the big thing. (Participant 7)

Carers observed that reduced pain had a major impact on social and family interactions, allowing the patient quality time with family and friends and to continue enjoyable activities. One of the key messages was that ETITDD enabled patients to remain themselves during the final stages of life:

We were able to go around and see some friends and she was able to go back home. She was able to come out (of the hospice) and actually her last day out was our daughter's 7th birthday ... It amazed many people that the picture on the front of our funeral service was taken that day because she looked so well with a nice smiley natural picture. (Participant 3 )

When considering the disadvantages of the ETITDD, one carer described an unexpected acute worsening of pain during titration, which caused considerable distress:

He came back from surgery and had it done (ETITDD insertion) and he was in so much pain it was terrible. I sat up all night and he was literally screaming ... for me that was the worst part. (Participant 10)

Carers reported their relatives experienced changes in bladder and bowel habit, which in two cases resulted in episodes of incontinence. Conversely, one carer felt that the patient's bowel habits had improved after ITDD insertion. Carers also described problems with the ETITDD system including frequent alarm activation, repeated disconnections or leakage around the line, resulting in suboptimal analgesia and unwanted admissions: 
It didn't seem to be working and they kept saying, oh you know, we will check it and adjust the doses, they knew they had to adjust the doses and he got up one day and they checked it and found the blue lines had come out and apparently they brought it up over his shoulder as I said he was a big fella, and obviously he had pulled it out and they had to redo the thing and repeat it all. (Participant 7)

There were two suspected cases of line infection requiring removal of the ETITDD, but this was not perceived as a significant issue by the carers interviewed:

I mean how many times does an intrathecal tube infect, percentage wise? So if its $10 \%$ or $5 \%$ then why bring it into the conversation. You can infect anytime, anything can infect, so it wasn't an issue. (Participant 8)

Two carers found it difficult to judge whether the ETITDD had been beneficial:

I can't say whether it really helped her pain or not but on the other hand what would she have been like and what sort of pain would she have been in if it hadn't been done? (Participant 2)

Other carers were very positive about the procedure, recommending it for others in a similar position. Those who reported significant complications believed that overall the benefits outweighed the disadvantages:

As I say it was the quality of life that improved no end really ... That six month period was not full of pain and discomfort. He was able to, although he was in bed, he was able to enjoy it. (Participant 5)

It's an individual choice, it's about quality of life and how you want to die. It is comparing a potential bit of quality time, or get it over and done with. At least there's a choice ... It is a very individual thing, unless it happens you don't know what you will be faced with. It's like any treatment there are positives and negatives, but when offered, most people will say yes. (Participant 9)

\section{Discussion}

This is the first study to explore family carer perceptions of ETITDD. ETITDD was perceived to be positive by the majority of carers, in very challenging, desperate situations. They recalled clear reductions in pain along with a reduction in systemic side effects. This echoes previous findings. 1,2 However, family carers focused mainly on QoL, both explicitly and implicitly and function during the interviews, which is not described elsewhere. ETITDD was valued most, when improved pain control allowed the individual to be themselves, particularly in social interactions. When carers felt this was achieved, significant side effects were considered acceptable. In one instance, the carer judged that the ETITDD was inserted too late for the individual to benefit in this way, but was still glad to have tried everything.

Healthcare professionals are often concerned with the over-medicalisation of patients towards the end of life. $\stackrel{12}{ }$ However, this was not a concern highlighted in our interviews. 
Overwhelmingly, family carers expressed the importance of a further option when other analgesic options had been exhausted. The interviews describe significant uncontrolled pain and side effects over time, and some concluded that ETITDD would have been beneficial at an earlier stage. This suggests a carer perception that physicians are considering ETITDD as a 'last resort' and the intervention is introduced at a time when informed consent maybe challenging to undertake. In further understanding how ETITDD impacts on QoL for the individual and their carers, we hope that palliative care teams will consider discussing difficult and challenging pain earlier in the disease trajectory. Exploration of the individual's priorities and goals, alongside evaluation of the options may lead to less suffering and loss of quality time in the last few months of life. Previous evidence suggests that clinicians do not openly discuss goals of pain intervention in this cohort of patients, $\underline{\underline{13}}$ although patients are clear that they wish to continue valued activities and socialising. $\underline{14}^{4}$

It is the clinical perception of the research group that on occasions, severe pain and medication side effects might be replaced with increased awareness of the situation. Some carers mentioned prolongation of life associated with ETITDD as found in previous studies $\underline{15}$ with advanced progressive disease but despite explicit exploration, the exchange of one distress for another was not a theme that emerged from the interviews. Both sites use a consent process that involves the relatives and actively manages expectations and this is likely to reduce the impact of exchange of distress. It is sometimes difficult to distinguish between medication side effects and deterioration due to terminal disease and for those patients whose survival exceeded expectations, implanted ITDD systems could have been considered.

The personal experiences of carers were also highlighted in the interviews. In contrast to the literature, none of the interviewees described caring as a burden. $\underline{13}, \underline{14}$ These families had access to specialist on call services and hospice admission, over and above normal provision for people at the end of life and carers recognised this. The enhanced support around this patient group may have led to a reduction in perceived burden for the carers.

When designing our study we debated, in the absence of any documented evidence, the optimal time to contact carers and invite them to participate in research following bereavement. The response rate to invitation was high and the data collected was rich, indicating they were willing to discuss their experiences. Two interviewees specifically commented that the timing of contact following bereavement (from 6 months onwards) was acceptable to them. It is difficult for us to comment on the reasons for nonparticipation as we did not seek to collect these data; however, it is the impression of the researchers that those who participated specifically wanted to recognise good experiences or explore difficult experiences and therefore there may be a range of more neutral views not presented here.

\section{Limitations}

Although recruitment occurred within 48 months, the variation in time between death of the patient and the carer interview was up to 56 months. While family carers appeared to have good recollection of information, we acknowledge that their recall of events over these time frames might have led to some data loss. The findings of this study are not 
intended to be generalised, but are likely to be transferable to other similar contexts and settings. The patients in this study all had external systems. Implanted systems are used elsewhere and caution is advised if applying data from this research to that group.

The research team included pain and palliative care physicians, bringing a variety of expertise and clinical experience to the research. We achieved a unified approach to the process through regular meetings. While this lengthened the analysis process, the final data interpretation incorporates varying professional viewpoints adding to the validity of the research.

We are mindful that we interviewed carer proxies rather than patients. Although the data are rich, there may be differences between patient and proxy accounts and perceptions. $\underline{16}$ Our study design has captured an array of experiences and if we had interviewed patients themselves, it is possible that only those with a good experience would be able to participate.

\section{Conclusion}

Carers described desperate situations before the ETITDD was placed, with significant loss of function and QoL in their relatives, secondary to uncontrolled pain and medication side effects. Carers perceived ETITDD to be of greatest value when it improved QoL for their relative, by reducing pain and the intolerable side effects of systemic analgesia, enabling individuals 'to be themselves' through their final illness and dying phase. Under these circumstances, carers deemed significant disadvantages to be acceptable. Carers also recognised the additional support and specialist care they received as part of the ETITDD service.

These findings add to the limited previous research around the experience of ETITDD as part of palliative care and will help inform healthcare professionals, patients and carers when considering analgesic options.

\section{Acknowledgements}

We would especially like to thank all the carers who participated in this study. We would also like to thank Carol Sandiford (Patient Advocate and Volunteer at Sue Ryder Hospice, Leckhampton) for her views and advice in the development phase of the study. We would also like to thank Dr James De Courcy (Consultant in Pain Medicine) for his assistance in recruiting the participants from Gloucestershire.

Author contribution

P.P. proposed the idea for the study. N.P., H.M., T.M. and P.P. developed the study. N.P., H.M. and M.H. conducted the in-depth interviews. Data analysis was conducted by N.P., H.M., M.H., T.M. and J.L.G.. N.P., H.M. and M.H. wrote the first draft of the manuscript and all authors contributed to the final paper. H.M. is guarantor. 
Declaration of conflicting interests

The author(s) declared no potential conflicts of interest with respect to the research, authorship and/or publication of this article.

Funding

The author(s) disclosed receipt of the following financial support for the research, authorship and/or publication of this article: We are grateful to Cornwall Hospice Care for funding transcription of those interviews taking part in Cornwall and travel costs for those taking place in the carers' home and to The Research and Development Department, Gloucestershire Royal Hospitals NHS Foundation Trust for funding transcription of local interviews. 


\section{References}

Smith TJ, Staats PS, Deer T, et al. Randomized clinical trial of an implantable drug

1. delivery system compared with comprehensive medical management for refractory cancer pain: impact on pain, drug-related toxicity, and survival. J Clin Oncol 2002; 20(19): 4040-4049. Crossref, Medline

Krames ES, Lanning RM. Intrathecal infusional analgesia for non-malignant pain:

2. analgesic efficacy of intrathecal opioid with or without bupivacaine. J Pain Symptom Manage 1993; 8: 539-548. Crossref, Medline

Breivik H, Cherny N, Collet B, et al. Cancer-related pain: a Pan-European Survey of

3. prevalence, treatment and patient attitudes. Ann Oncol 2009; 20(8): 1420-1433. Crossref, Medline

Zech DF, Grond S, Lynch J, et al. Validation of World Health Organization Guidelines for

4. cancer pain relief: a 10 year prospective study. Pain 1995; 63(1): 65-76. Crossref, Medline

Meuser T, Pietruck C, Radbruch L, et al. Symptoms during cancer pain treatment

5. following WHO guidelines: a longitudinal follow up study of symptom prevalence, severity and etiology. Pain 2001; 93(3): 247-257. Crossref, Medline

6 Courcy JG. Interventional techniques for cancer pain management. Clin Oncol 2011; 23:

-417. Crossref

Valeberg BT, Rustoen T, Bjordal K, et al. Self reported prevalence, etiology and

7. characteristic of pain in oncology outpatients. Eur J Pain 2008; 12(5): 582-590. Crossref, Medline

British Pain Society. Intrathecal drug delivery for the management of pain and spasticity 8 in adults; recommendations for best clinical practice, https://www.britishpainsociety.org/static/uploads/resources/files/itdd 2015 pro v3.pd $\underline{f}$

Hawley P, Beddard-Huber E, Grose C, et al. Intrathecal infusions for intractable cancer

9. pain: a qualitative study of the impact on a case series of patients and caregivers. Pain Res Manag 2009; 14(5): 371-379. Crossref, Medline

10 Hynson JL, Aroni R, Bauld C, et al. Research with bereaved parents: a question of how not why. Palliat Med 2006; 20: 805-811. Link

11 Braun V, Clarke V. Using thematic analysis in psychology. Qual Res Psychol 2006; 3: 77101. Crossref

12 Fried TR, Bradley EH, Towle VR, et al. Understanding the treatment preferences of seriously ill patients. N Engl J Med 2002; 346: 1061-1066. Crossref, Medline

13 Bhatia R, Reid CM, Gibbins J. Goal setting for patients with palliative care needs. GM 2014; 2, https://www.gmjournal.co.uk/goal-setting-for-patients-with-palliative-careneeds

14 Gibbins J, Bhatia R, Forbes K, et al. What do patients with advanced incurable cancer want from the management of their pain? Palliat Med 2014; 28(1): 71-78. Link

15 Cahana A, Arigoni F, Robert L. Attitudes and beliefs regarding the role of interventional pain management at the end-of-life among caregivers: a 4-year perspective. Pain Pract 2007; 7(2): 103-109. Crossref, Medline 

evaluations of patients' pain, anxiety and depression. J Pain Symptom Manage 2004; 28(2): 104-114. Crossref, Medline 